\title{
3D MODELING FOR THE KNOWLEDGE OF ARCHITECTURAL HERITAGE AND VIRTUAL RECONSTRUCTION OF ITS HISTORICAL MEMORY
}

\author{
M.Campi ${ }^{a}$, A. di Luggo ${ }^{b}$, S. Scandurra ${ }^{\text {c }}$ \\ ${ }^{a}$ DiARC, Department of Architecture, University of Naples Federico II, campi@unina.it \\ ${ }^{\mathrm{b}}$ DiARC, Department of Architecture,, University of Naples Federico II, antonella.diluggo@unina.it \\ ${ }^{c}$ DiARC, Department of Architecture, University of Naples Federico II, simona.sca@tiscali.it
}

Commission II

KEY WORDS: Architectural heritage, Range-based survey, 3D modeling, Virtual reconstruction, Palazzo Penne

\begin{abstract}
:
The object of this paper is one of the most ancient palaces of Naples, Palazzo Penne, a fourteenth-century residential building located on a small high ground which originally was in the outer fringe of the built up area in a privileged position enabling to enjoy the landscape and gulf beauty. This building, which today is in the heart of the historical center, was the subject of an extensive analysis and documentary research, as well as of metric laser scanner survey carried out by the group researchers working at the Interdepartmental Centre of Research Urban Eco of the University of Naples Federico II.

Starting from scan to bim systems the creation of a parametric model of the current state of the building is completed, by bringing the point cloud elements back to objects to which historical and construction data can be associated.

Moreover starting from acquired data, the 3D model shows the reconstructive hypothesis of the original structure and the virtual reconstruction of the building based on traces found on-site and on the comparison with coeval creations allowing to properly hypothesize the design of point features.
\end{abstract}

\section{INTRODUCTION}

Modelling in architecture allows to study an artifact in all its metric and materic specifications as well as in its volumetric organisation. It also allows to investigate reality well over its contingent physical form. This is precisely why there are studies in architecture and archaeology aimed at giving reconstructive hypotheses based on specific studies and researches and on latest generation modelling and survey technologies.

Therefore the historical centre of Naples is a particularly significant study field for the important transformations involving its architectures that still today show the traces of interventions and modifications occurred over the centuries.

The object of this essay is one of the most ancient palaces of Naples, Palazzo Penne, a fourteenth-century residential building located on a small high ground which originally was in the outer fringe of the built up area in a privileged position enabling to enjoy the landscape and gulf beauty. This building, which today is in the heart of the historical centre, was the subject of an extensive analysis and documentary research, as well as of metric survey carried out by the group of teachers and researchers working at the Interdepartmental Centre of Research Urban Eco of the University of Naples Federico II.

\section{RELATED WORKS AND WORK AIMS}

During the last decade, several surveys systems have been described in their application in cultural heritage investigation, combining different type of sensors, from active ones such as terrestrial laser scanning (TLS), to passive ones such as photogrammetry mapping mobile systems (Remondino, 2011). As known, each of these techniques has its own advantages and it is now understood that the combination of those can amplify the benefits coming from each of them (Cappellini et al., 2011). In this way it is possible to obtain, starting from survey to $3 \mathrm{D}$ modeling, the best result in terms of single precision data, of overall accuracy as well as of the entire process optimization. In this regard, the scientific community have given relevant improvements in the performance and practises that gives advantages in terms of precision, accuracy, costs, acquisition and processing times, which are always essential requirements Remondino, et al., 2014; Guidi, et al., 2014; Fassi, et al., 2013). The many surveys the work team made of the most representative monuments of the city of Naples and of the surrounding area (from the coast to Pompeii), using different tools and techniques (from UAV to Laser scanner, from digital photogrammetry to Lidars) constitute the works related to this one. Despite of all existing techniques, the required accuracy for modeling and representing wide areas suffers so far from a lack of convergent protocols, able to take better advantage of existing hardware and software technologies.

Many other studies have theorized the potential of the laser scanner techniques and other techniques in the architectural survey field (Andrews et ali., 2013; Cardaci et al., 2013; De Luca et al., 2016; Rinaudo et al., 2007; Andrews, D et al., 2010) The authors of this essay had different experiences in this research field, in collaboration with international teams too.

The aims of this survey were in solving serious problems of ambient conditions in which the works have been operated. Integrated advanced surveying methodologies are, in the domain of archaeology and architecture, an exponential field of application and interest. Creating and reasoning upon 3D models - within powerful CAD tools - is today one of the major cornerstone of human collaborative interactions. Integrated information and data, coming from different instruments and sensors, are also fundamental to generate appropriated H-BIM, dedicated to monitoring and restoration of huge monuments.

Palazzo Penne, just after the first visits of the scientific team, demonstrated very soon to require different approaches and procedures in processing $3 \mathrm{D}$ digital documentation. The condition presented characteristics that could be compared to the ones you find in cave surveying: narrow spaces, poor 
illuminated, with a very high complex degree in movements and obstacles. Another condition that constitutes an aspect of importance of the work is that Palazzo Penne is one - perhaps the most important - of the few mediaeval legacy of the typology of "palazzo" in Naples, still preserved, even if a structural very bad situation that deserves an urgent attention in terms of documentation, we have to say very lacking until now. The use of phase-shift laser scanning demonstrated to be appropriate for reveal these interiors that presented conditions, that look like to some underground 3D structures (Rodriguez et al., 2015, Zlot, R., Bosse, M., 2014. Three-dimensional mobile mapping of caves. Journal of Cave and Karst Studies, v. 76, no. 3, p. 191-206).

These systems offer the record of detailed information with the maximum accuracy, which fits necessarily with the goals related to a restoration and to a structural re-functionalization of the monument.

\section{AREA OF STUDY}

The main body of Palazzo Penne, which is a part of the original structure, is located on an elongated unit and it covers a difference in length of several meters from upstream to downstream.

The Palace is inside a block of buildings of great architectural importance, such as Palazzi Amendola and Casamassima and the churches of Santi Cosma and Damiano and San Pietro in Vincoli and Santi Demetrio and Bonifacio. And precisely this church is in part linked to the history, the origin, and the transformations of Palazzo Penne.

Palazzo Penne is a rare example of civil Durazzo architecture and a significative evidence - in its surviving parts - of the first Renaissance in Naples. Its name derives from the man who wanted to build it, Antonio da Penne, a historical figure from Abruzzo, an exponent of the cultivated forensic bourgeoisie who came in Naples following King Ladislao of AngiòDurazzo, as his secretary and personal advisor. The construction of this building is attributed to Antonio Baboccio from Piperno and, according to Celano (Celano, 1856), it dates back to 1380 , whereas the inscription on the entrance portal indicates 1406 as the year of its conclusion: Twentieth year of "King Ladislao's reign..." "XX anno regni regis Ladislai sunt domus haec facte nullo sint turbine fracie mille fluunt magni bistres centum quater anni".

Historical sources indicate that the Penne family maintained their ownership of this building until the mid-sixteenth century, selling it in 1562 to Rocco family of Seggio di Montagna. Subsequently passed into Capano family ownership, the building was bought in 1685 by the Somaschi Fathers of the near church of San Demetrio and Bonifacio, who gave rise to important transformations by deeply altering its original structure.

Historical cartography of Naples is generally an useful tool for understanding transformations, while in this case is only a partial support because of the significant modifications the building underwent and the absence of definite reference elements. XVI and XVII century representations clearly show the sector to which the building belongs, also thanks to the presence of the recognisable neighbouring monuments of $\mathrm{S}$. Giovanni Maggiore and S. Maria la Nova, the palace of Tesoriero and the church of S. Pietro in Vincoli. These monuments allow to easily identify the urban area bounded by ways which will become more definite over time, such as the hill of Pendino Santa Barbara and the via Sedile di Porto. According to the available studies, it seems reasonable to assume the presence of an original courtyard structure, which can be observed both in the view of Lafrery (1565) and in the view of Baratta (1629). In the absence of other historical documents, unfortunately, cartography is not sufficient for supporting this assumption, based on the interpretation of marks without a recognisable codification and geometrical rules allowing to conveniently read representation.

The map by Duca di Noja (1775) illustrates a strongly different situation, where this Palace is represented according to its arrangement after the deep transformations carried out by the Somaschi Fathers, which is few different from the present building. It is mainly arranged on a rectangular structure which, adapting to the sloping ground, from one side, skirts and underlines the way of Pendino, from the other side, it faces the large inner garden.

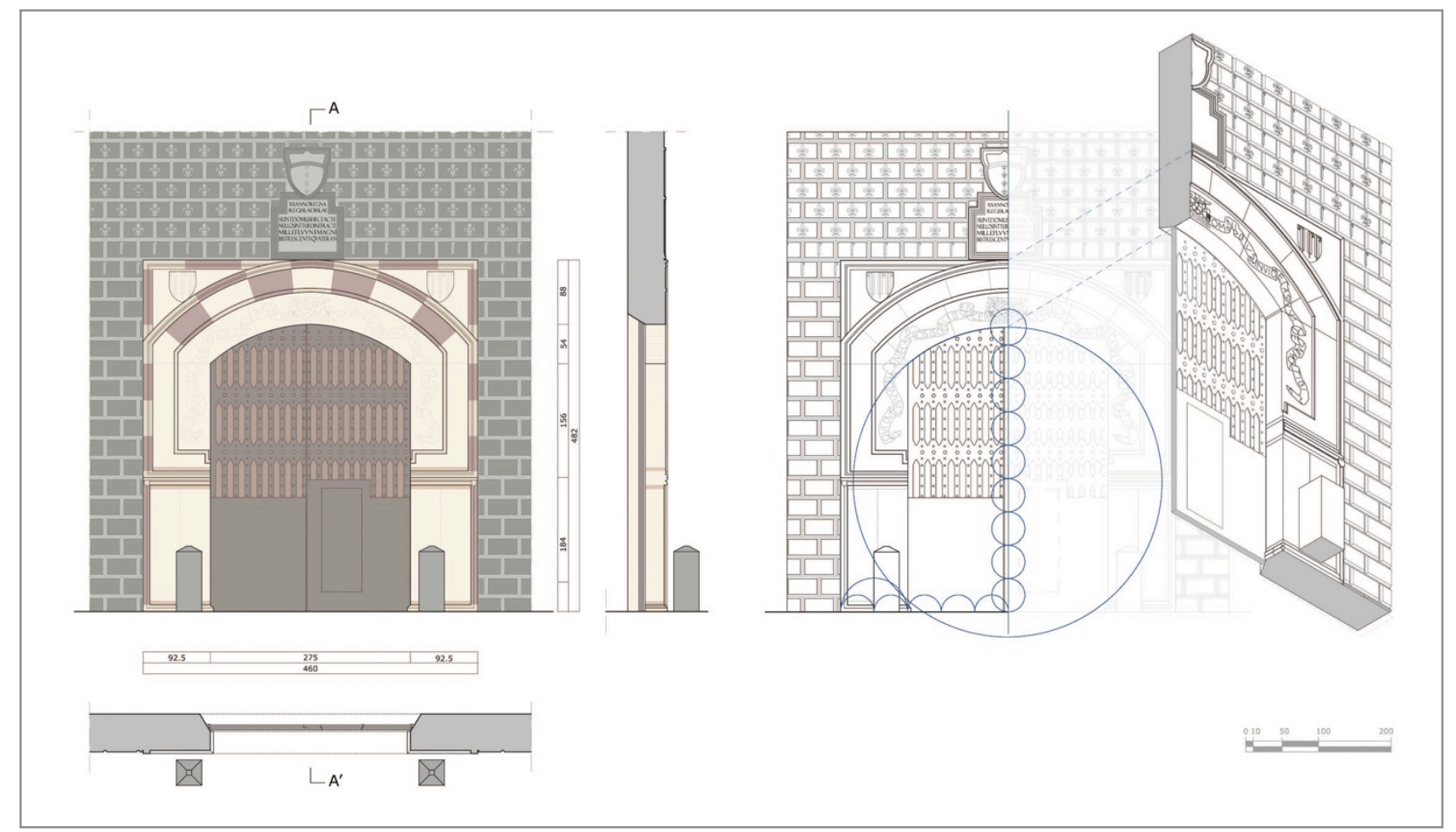

Figure 1. Palazzo Penne, entrance portal, drawings by Giuseppe Galzerano 


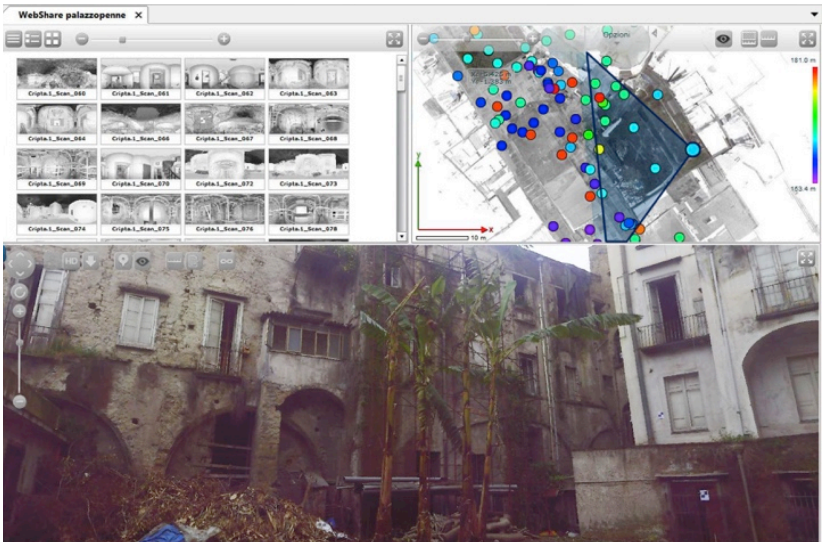

Figure 2. Palazzo Penne, internal courtyard. WebShare screenshot

This building remained the property of the Somaschi Fathers until 1806 when it was bought by the abbot and volcanologist Teodoro Monticelli, who gave his name to the square facing the building and who lived in it until his death in 1845 .

Since 2002 the building is property of Regione Campania which has recently arranged a restoration project in consideration of the significant alterations carried out in the years after 2000 by previous owner Institutions and of its strong decay.

\section{SURVEY METHODOLOGY}

This building was the subject of a careful survey campaign by Focus 3D scanner laser through which a certain number of scans were carried out thus enabling to acquire many information. In particular, in addition to the range based survey, the severe decay of this building and the presence of many props in its rooms required further metric surveys, by performing effective controls with traditional methods and photomodelling techniques.

A resolution of one point every $6 \mathrm{~mm}$ to 10 meters was set by using six spherical magnetic-based targets and paper chessboard targets for the union and referencing of point clouds. It has been verified that a same triad of targets was always visible on couples of consecutive shots.

Survey campaign took place in several days and processing data led to a dense pointcloud from which to extract metric and materic data. This survey was carried out starting from the square facing the building and continuing beyond the first courtyard, in the internal rooms on different levels, in basements, completing information through further shots from the inner garden, the roof of the building and along the Pendino hill.

Data were processed through several softwares (Faro Scene, Pointools, Pointcab), by recording point clouds in one reference system and by exporting the resulting three-dimensional model in formats that are compatible with other processing softwares. In particular, clipbox options allowed to conveniently read the several parts of the monument, just as the visualization in Pointcab made it possible to read and understand the different levels and the relationship between them.

Tunnels, depots or disused spaces characterise the basement structure on different levels along the Pendino hill. Only data processing, reading and interpreting acquired images allowed to understand their location. The survey carried out in the basement showed rooms that have been walled for several decades, after they have been used as deposits of waste material. Originally inaccessible, these spaces were found by opening a gap in the wall. Moreover, near the cellars, the ancient underground cisterns were found and surveyed together with their channels providing water to the entire building for those who lived in it and for irrigating the luxuriant garden.

As to the Pendino hill, whose extremely limited road section seemed to made the facade survey impossible, scanner was used in different ways and with diverse inclinations, on the roof and beyond the openings on the alley. This made it possible to acquire a point cloud with data useful for processing the front having two crossed windows typical of the original structure. These operations were opportunely planned with reference to the positioning of targets and scan points, in such a way as to have a good overlapping between them and the presence of a great number of targets in each of them.

In consideration of the precarious state of conservation of this structure and the characteristics of some very restricted places, laser scanner survey has proved to be particularly suitable for obtaining accurate information extremely quickly, by acquiring a significant amount of data useful for studying the entire building, with the possibility of distinguishing the additions and the transformations carried out over the centuries.

This survey allowed to experiment different representations, starting from traditional elaborations (plans and sections) based on orthophotos, to highlight the multiple features of the artifact,

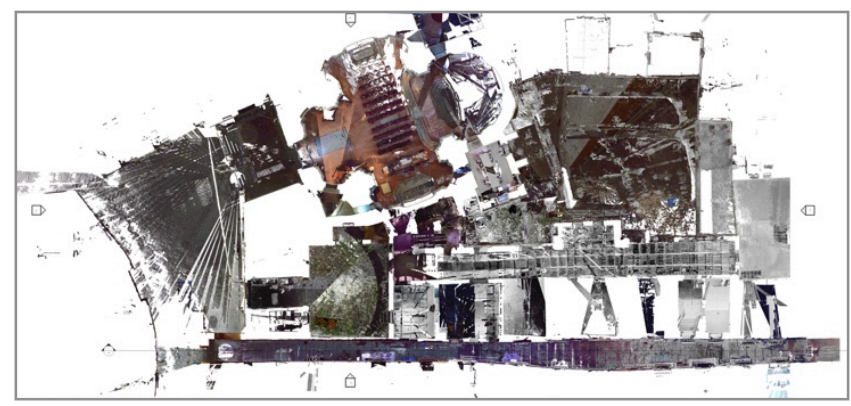

Figure 3. Palazzo Penne, plan view. Pointcloud in Autodesk Revit. Processing: C. Tarantino, M. Pulcran

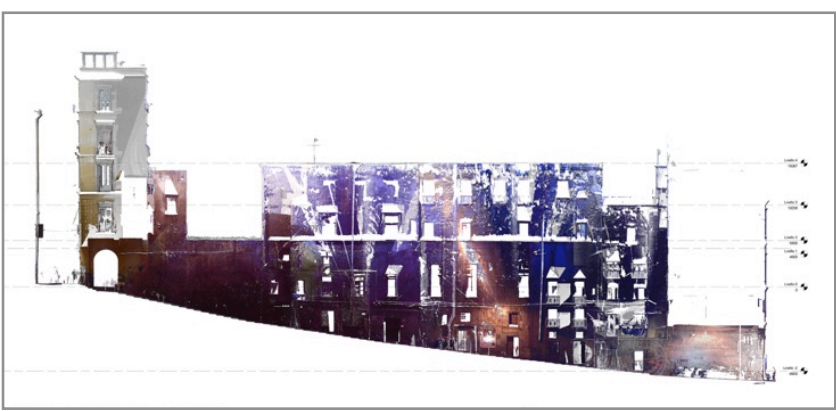

Figure 4. Palazzo Penne, elevation view. Pointcloud in Autodesk Revit. Processing: C. Tarantino, M. Pulcrano

up to three-dimensional modelling. This latter was extremely important not to describe the system, but rather to understand its complex structure and form, also with a view to verify the reconstructive hypothesis of the original building. 


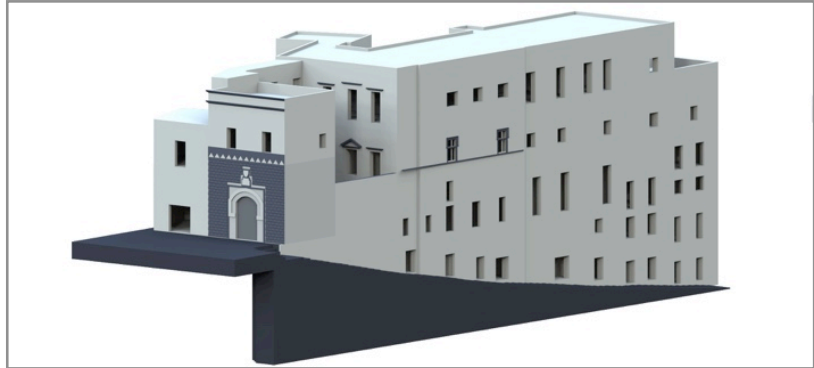

Figure 5. Palazzo Penne, view on Pendino Santa Barbara alley. Modeling by S. Scandurra

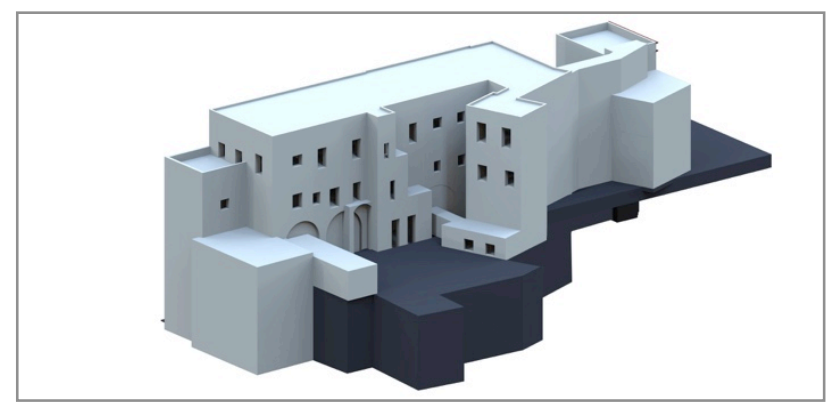

Figure 7. Palazzo Penne, view of the internal courtyard. Modeling: S. Scandurra

This study benefited from further contributions which made it an interdisciplinary work since it was carried out in cooperation with Structural Engineering Department of the University of Naples Federico II. Therefore these data were integrated with additional constructive and structural information, concerning the types of masonry (thickness, typology and materials), horizontal structures (wooden ceilings, vaults), horizontal elements (architraves, arches) and any other information defining an overall framework of this building even from a structural point of view. These data were acquired through in situ surveys such as endoscopic procedures and verifications with flat jacks to determine masonry tension.

This survey was therefore performed taking into account more

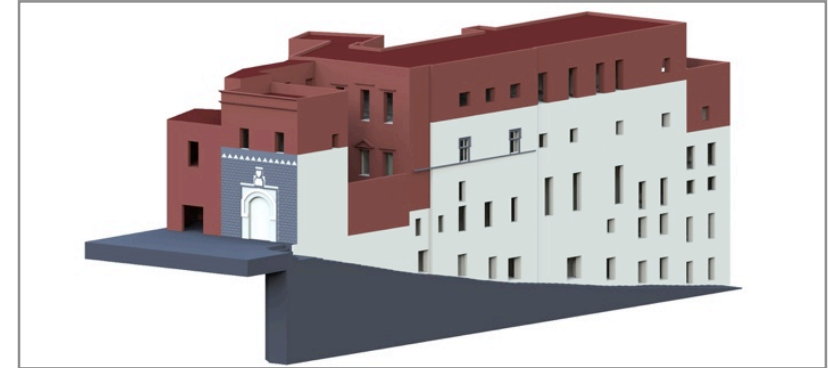

Figure 6. Palazzo Penne, view on Pendino S. Barbara alley, eighteenth-century additions. 3D Modeling by S. Scandurra

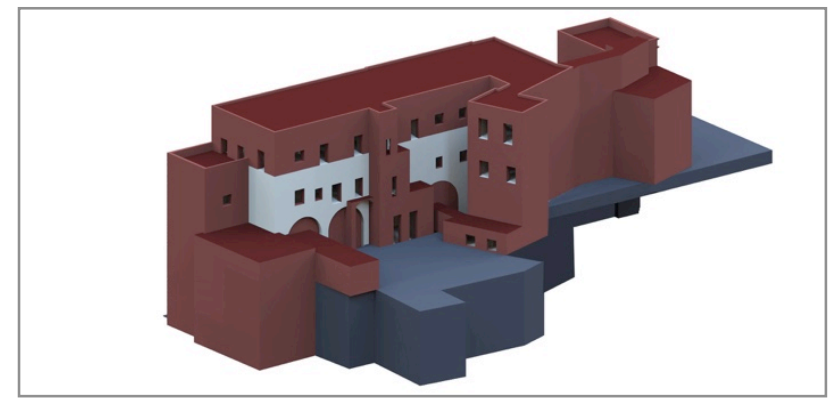

Figure 8. Palazzo Penne, view of the internal courtyard, eighteenth-century additions Modeling by S. Scandurra

aspects, investigating each element in its structural role and obtaining a knowledge useful to any future restoration.

\section{DATA PROCESSING AND PRODUCTS}

The hypotheses of reconstructions are based on the results of the survey compared with the original documents about the building which were found in the State Archive in Naples, in particular the expertise of the Tavolario Gallarano written for the appraisal of the building on October 2nd, 1662, because of an argument between the heirs of the owners and their creditors resulting in the sale of the palace to the Somaschi Fathers.

For over a century, these latter carried out substantial changes

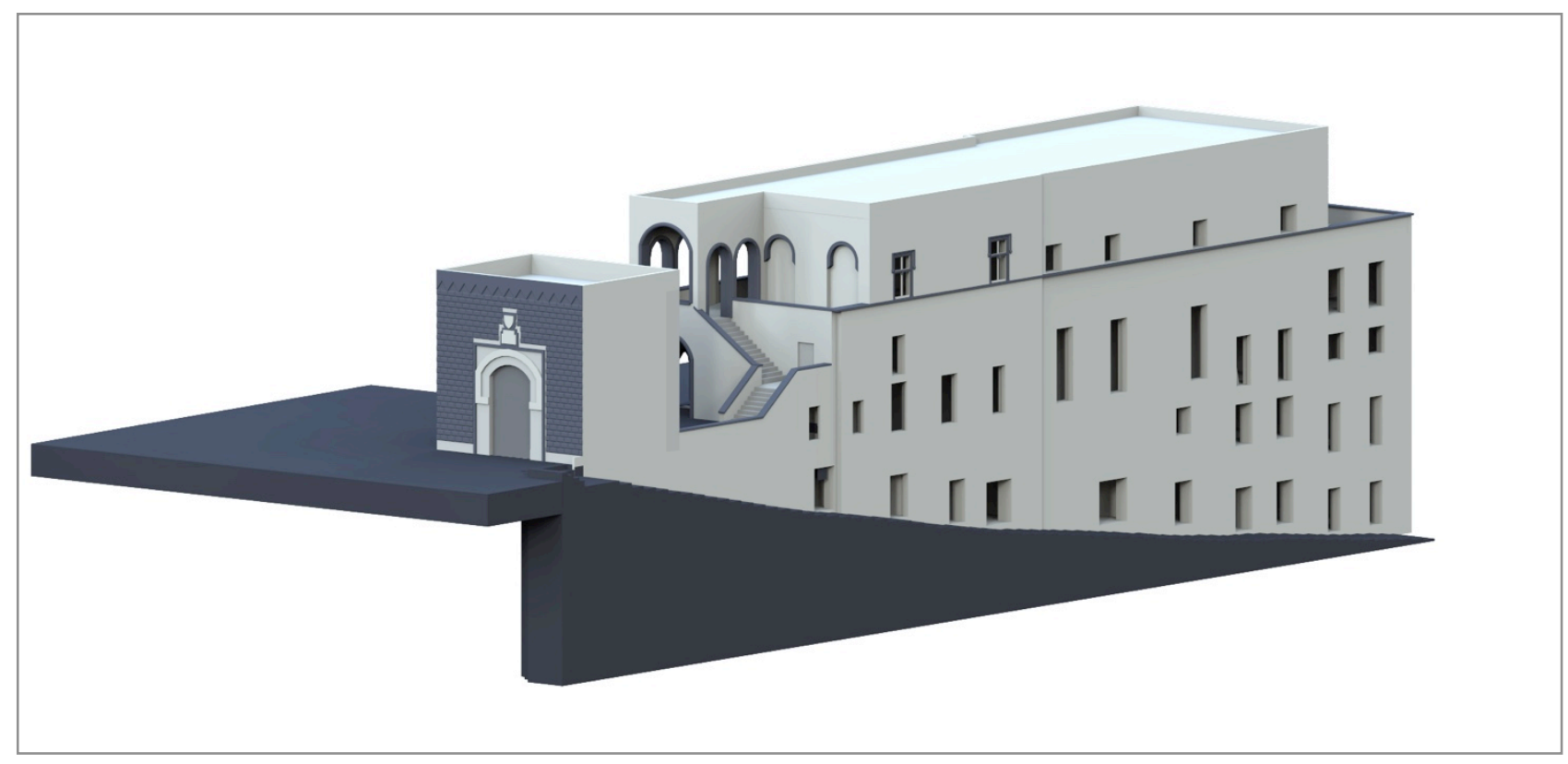

Figure 9. Palazzo Penne, reconstruction of the original configuration on Pendino alley. Modeling by S. Scandurra 
of the building to adapt it to the specific needs of novitiate. The survey carried out allowed to understand transformations, some of which can immediately be seen in the interventions that visibly altered the whole structure, some others highlighted by clues such as the different masonry thickness, the new inner walls and particular plaster treatments.

A chronological mapping was prepared concerning its modifications and in particular: the addition of a new level over the entrance area and the modifications of the vaulted hall with two new spaces; the construction of the vaulted trapezoidal stair designed by Giambattista Nauclerio, one of the most important architects in Naples in the eighteenth century; the building displacement to the front of the main courtyard and the modification of the access to the building with the demolition of the ancient loggia and the creation of a different connection with the upper floor; the closing of the loggia on the garden and the construction of a new structure to host novices; the elevation of the southern wing of the building.

The identification of in situ traces and transformations carried out over time, as well as the comparison with coeval buildings, enabled to virtually rebuild the original structure, which probably included a double row loggia overlooking the luxuriant inner garden, in addition to the one Gallarano indicated in the first courtyard.

Studies and evidences suggest that, already in the original construction, the entrance to the building was in the highest part of the slope, along the present via Donnalabina through a small structure facing Largo Teodoro Monticelli. This building anticipated the real palace whose access was after the main courtyard and it was a sort of entrance pavilion, having a symbolic role, as a reinterpretation of the triumphal arch marking the access to the residence. In the eighteenth century, when deep transformations involved the whole building, a further level above the cornice was added to this structure, and it can be seen on the front through two openings.

The basement remained instead unchanged and, still today, on the stone ashlar the white and rosy marble portal stands out, designed by a segmental arch with a wide moulding, inscribed in a rectangular cornice according to a typically Durazzo composition. The ashlar is composed of piperno and trachyte stones protruding from the wall and alternately arranged, similarly to what can be seen in Palazzo Diomede Carafa in Naples. In its lower part, the ashlar shows the symbols of the Penne family, and, in its higher part, the Anjou lilies. The original front is delimited by a cornice characterised by small gothic trefoil arches, and above them, rich symbols together with the underlying part made the façade of the building a page of history of the city, of the palace, and its first owners.

In particular, a first strip contains the symbols composing the Durazzo coat of arms (such as the Jerusalem cross, the Anjou lilies and the striped field) and above the symbol of king Ladislao's crown. Over the portal, the façade ends with an inscription indicating the year in which the palace was built and the Durazzo coat of arms. The sovereign concession of decorating the building with the arms and the symbols of the royal family, as well as the approval of the Penne coat of arms, meant the eternal protection to the Penne family.

As regards the portal, according to Borrelli (Borrelli, 2000) some works in Piazzetta Teodoro Monticelli brought to light traces of the original pavement at a depth of about $50 \mathrm{~cm}$ in comparison with the present one. This information not only would enable to identify the original depth of the palace but it also would explain some anomalies showed by the study of the portal and by the comparison with similar examples in Naples, since the stylobates of the pillars are excessively small and, what is more, the study of relationship suggests that the passage room was higher.

Furthermore, the survey brought to light several anomalies in the front, where the portal, the coat of arms and the marble inscription don't seem to be congruent with the ashlar and this suggests that these elements were located later.

Once crossed the entrance, the passage to the courtyard was marked by a large cross vault whose profile designed on the internal front a majestic ogival arch, as wide as the extension of the entire pavilion.

At present, on the internal facade of the courtyard there are still signs of its original mouldings although the arch and the ridge of the same vault can be seen only in the central part, due to the addition of two side blocks, built to support a new level built in 1740 .

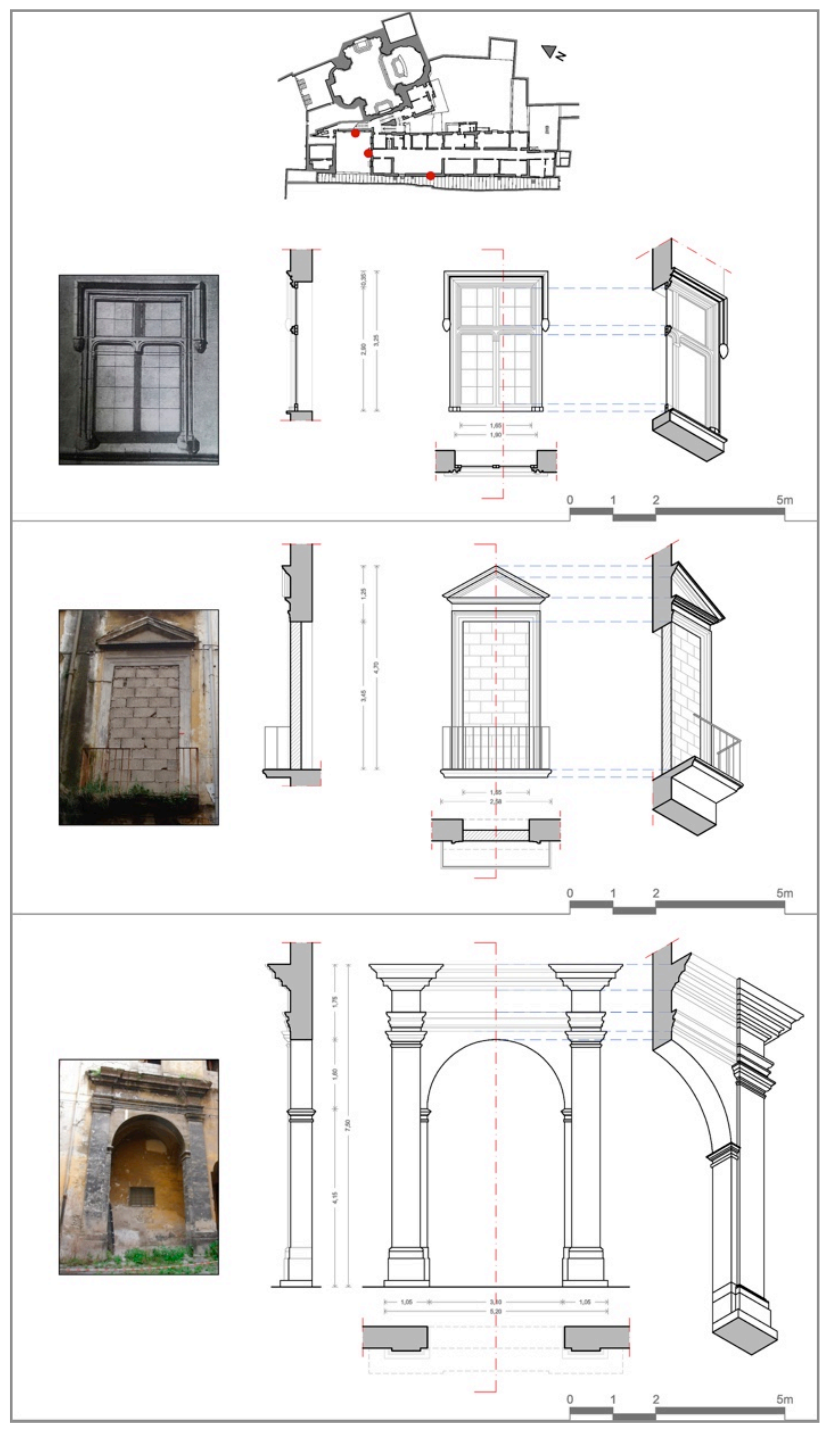

Figure 10. Abacus of openings. Drawings by C. Tarantino, M. Pulcrano

The survey and the reconstruction in a 3D model made it possible to understand the original access to the building, which was precisely aimed at giving an amplified perception of space. Across the entrance portal, in fact, the cross-vaulted lobby expanded the view, beyond the main courtyard, towards the inner façade framed by the majestic arch. 
As regards the reading of the present condition, it is clear that the transformations carried out over the centuries substantially altered the overall design: as mentioned before, the large cross vault was considerably reduced, thus making the lobby a simple passage; the new annexe, built in the main courtyard instead of the loggia, modified perspective, also in consideration of the addition of a new level making the annexe disproportionate to the opposite space reducing perceptively the main courtyard to a narrow space; the symmetry of the new façade, given by three openings for each level of which the central one is underlined by a pediment, makes the composition a rigid system which does not allow to understand the magnificence of the original work.

The entrance arch showed a piperno loggia which could be reached through a stair also in piperno, with two flight leading to a mezzanine and ending to a large walkway on the courtyard. This walkway led to a second loggia which, overlooking the inner garden, offered access to the various rooms and led to a large hall, existing still today, on the first floor. Gallarano's expertise suggests that the present portico overlooking the ground floor garden was also repeated on the upper floor with a loggia, and this hypothesis could be confirmed by the few figurative elements in the already mentioned views of Lafrery and Baratta, suggesting the presence of a double loggia on a plan centered on the courtyard, which the arches facing the garden could refer to.

In the eighteenth century, the radical transformations operated by the Somaschi Fathers resulted in the destruction of the piperno stair and of the main courtyard loggia. They were replaced by a new structure eliminating the original fifteenthcentury composition with the decorations in piperno, by designing a new one, completely plastered and characterised by openings with balconies, highlighted by pediments and cornices. Today two piperno arches incorporated in the new building are what remains of the pre-existing stair. Once they were aimed at support the walkway overlooking the first courtyard and they were shaped similarly to the big piperno arches facing the garden, one of which is partly hidden by the eighteenth-century stair, to release the first level of the palace from the remaining ones. The second of the two arches is visible, and still today leads to the lower floor, originally created for the cellars. Below the original stair, a small gap led to a colonnaded corridor with arches, giving access to a garden decorated with roman statues.

The façade loggia defined a double level of depth: the external level and the rear one, and, what is more, the asymmetric position of the entrance stair further enlarged the view along the diagonal of the courtyard. Moreover, below the walkway, a visual channel drew attention to the large inner garden, placed under the level of the first courtyard.

In 1709 the architect Gianbattista Nauclerio was commissioned to demolish the structures placed in the north-eastern angle of the building to erect the new church of SS. Demetrio and Bonifacio, whose construction was already previously started, by bringing it back with respect to the first annexe. Always in those years, Nauclerio himself builds, in a narrow trapezoidal space, a new staircase to connect the novitiate building with the church and the ancient palace, until the third level added by the Somaschi Fathers to be used as kitchen and refectory. On this occasion, the inner stair leading to the cellars and whose existence was proved by the survey and by Gallarano was destroyed. Furthermore, a portion of the space originally used for the cellars is made open-air, in order to air and to lighten the lower floors of the novitiate building, constructed near the church of the SS. Demetrio and Bonifacio, thus creating a little space below the garden.
Today to enter the garden it is necessary to pass through a narrow ramp leading to the lower floor, whereas at present the trapezoidal stair is the only way to reach the upper floors since even the pre-existing eighteenth-century stair together with the fifteenth-century one has been demolished.

According to the survey, these transformations have been progressively generated by specific functional and distributive needs and they are not the result of a single project. Furthermore, it is clear that, once become the property of the Somaschi Fathers, the building changed into a dependance at the disposal of the nearby Church which was the real entrance to the entire complex.

In this new arrangement, Gianbattista Nauclerio's stair has a basic role not only for the intelligence of its composition and structure but also for the will to recompose the "pieces" in a single system. As the new heart of the complex, in fact, from the ground floor the stair allows to reach the cellars, the two levels of the ancient palace and the third floor, added by the Padri Somaschi; at the same time it leads at the various floors of the novitiate building by creating a direct connection with the church and with the new level of the entrance pavilion. This is an important architectural work which develops in space, but, at the same time, completely ignores the pre-existing structures.

\section{CONCLUSIONS}

The above information clearly indicate that Palazzo Penne itself is a very complex system and with the many modifications occurred over time constitutes an interesting sample of study from the metric, historical, and methodological point of view. The documentary inputs, material traces and survey data don't allow a diachronic description of the palace and its building phases. Therefore the support of multidimensional documents (3D, 4D, 5D) was immediately necessary for understanding the current state of the building, its original structure and its management.

Considering the significant difference of level between the two extremities of the building, together with the presence of rooms placed at different levels it is possible to understand that the sole bidimensional representations, such as plans and sections, are not sufficient to give information.

Given the amount of information about the metric, materic and structural data and in consideration of a desirable restoration work, in addition to the traditional modelling, the research group arranged a parametric modelling in Revit Autodesk to understand the architectural system in its entirety and the features of its single elements.

This was carried out by bringing point cloud elements back to morphologically recognisable objects to which historical and construction data have been associated. In this way, a data bank of the whole building was implicitly created, in order to have an information system based on elements that are ontologically defined not only in their dimension and functions but also in their mutual relationships, as well as in materials and intrinsic characteristics.

The creation of a model in H-BIM environment allows to enrich an interdisciplinary knowledge on architectural heritage, resulting in a systematic reading of built environment, where a model is created for its meaning rather than for its shape and geometry, since its definition necessarily requires the ontological identification of the individual parts and the connections linking them and referring to them in their lexicon and semantics.

Moreover starting from acquired data the 3D model shows the reconstructive hypothesis of the original structure and the virtual reconstruction of the building based on traces found on- 
site and on the comparison with coeval creations allowing to properly hypothesise the design of point features.

In particular the reconstruction addresses the main point of the entrance with the gray marble loggia and the access to the upper rooms, the system of the ways linking the slopes where the building is located and it gives a virtual documentation including multidisciplinary data and able to preserve the memory of the ancient structure also for its current promotion and management.

\section{ACKNOWLEDGMENTS}

The authors want to thank everybody from the team that supported architectural survey operations. Acknowledgments to Raffaele Catuogno, who supported the survey by laser scanner and the following operations of post processing.

This research is part of an investigations in cooperation among the Region of Campania, Diarc, Department of Architecture, and Research Center Urban/Eco of the University of Naples Federico II (Italy).

\section{REFERENCES}

Andrews, D.P., Bedford, J., Bryan, P.G., A comparison of laser scanning and Structure from Motion as applied to the great barn Harmondsworth, UK. In: International Archives of the Photogrammetry, Remote Sensing and Spatial Information Sciences, Volume XL-5/W2, 2013, pp. 31-36

Andrews, D et al 2010 Measured and Drawn : Techniques and Practice for the Metric Survey of Historic Buildings (2 edn). Swindon: English Heritage

Borrelli, G., 2000. Il Palazzo Penne. Un borghese a corte, Arte Tipografica, Napoli.

Cappellini, V., Campi, M., 2011. 3D Survey of the San Carlo Theatre in Naples. In: Int. Archives of Photogrammetry, Remote Sensing and Spatial Information Sciences, XXXVIII-5/W16, pp. 91-97.

Cardaci A., Versaci A. 2013. Image-based 3D modeling vs laser scanning for the analysis of medieval architecture: the case of St. Croce in Bergam. In: International Archives of the Photogrammetry, Remote Sensing and Spatial Information Sciences, Volume XL-5/W2, 2013XXIV International CIPA Symposium, Strasbourg, France.

Celano, C., Chiarini, G.B., 1856-60. Notizie del bello dell'antico e del curioso della città di Napoli, con aggiunzioni di G.B. Chiarini, Napoli, IV, pp.55-57.

Cuccaro, A., 2008. Palazzo Penne e l'edilizia residenziale in età durazzesca a Napoli, in P. F. Cristilli, F. Manzari, Curzi G. (a cura di), Universitates e baronie, Arte e architettura in Abruzzo e nel Regno al tempo di Durazzo, Vol 1, Pescara

Dallas, R W A 2003 A Guide for Practitioners: Measured Survey and Building Recording. Edinburgh: Historic Scotland

De Luca, L., Carboni, N. Towards A Conceptual Foundation For Documenting Tangible And Intangible Elements of A Cultural Object, in Digital Applications in Archaeology and Cultural Heritage 3(4), 2016. DOI:10.1016/j.daach.2016.11.001

di Luggo A., Catuogno R., From point cloud to HBIM. Survey and modeling for the knowledge and management of architectural heritage, in Empler, T., 3D Modeling and BIM, Applicazioni e possibili futuri sviluppi, Roma 2016- ISBN 9788849619317

di Luggo A., Scandurra S., The knowledge of the architectural heritage in HBIM systems from the discrete model to the parametric model, «DISEGNARE CON», vol. 9 / n.16 -ISSN $1828-5961$

Fassi, F., Fregonese, L., Ackermann, S., De Troia, V., 2013. Comparison between laser scanning and automated 3D modelling techniques to reconstruct complex and extensive cultural heritage areas. In: Int. Arch. of Photogrammetry, Remote Sensing and Spatial Information Sciences, 40(5/W1), pp. 73-80.

Guidi, G., Russo, M., Angheleddu, D., 2014. 3D survey and virtual reconstruction of archaeological sites. Digital Applications in Archeology and Cultural Heritage. http://dx.doi.org/10.1016/j.daach.2014.01.001

Heritage, G and Large, A 2009 Laser Scanning for the Environmental Sciences. Chichester: Wiley Blackwell

Pane, R., 1937. Architettura del Rinascimento a Napoli, Napoli

Rago, G., 2012. La residenza nel centro storico di Napoli dal XV al XVI secolo, Carocci Editore, Roma.

Remondino, F., 2011. Heritage Recording and 3D Modelling with Photogrammetry and Laser Scanning. In: Remote Sensing, 3(6), pp. 1104-1138.

Remondino, F., Campana S., 2014. 3D Recording and Modelling in Archaeology and Cultural Heritage. Theories and best practices. Archaeopress.

Rinaudo, F., L. Bornaz, and P. Ardissone, P., 2007. 3D high accuracy survey and modelling for Cultural Heritage Documentation and Restoration. In Vast 2007-future technologies to empower heritage professionals, , Brighton, UK, Archaeolingua Hun, pp. 19-23.

Rodrìguez-Gonzàlvez, P., Nocerino, E., Menna, F., Minto, S., Remondino, F., 2015. 3D Surveying \& Modeling of Underground Passages in WWI fortification. In: The International Archives of the Photogrammetry, Remote Sensing and Spatial Information Sciences, Vol. XL-5/W4, pp.17-24.

Rosi M., L'altro Rinascimento, Architettura meridionale nel '400, Napoli 2007.

Shan, J and Toth, C 2009 Topographic Laser Ranging and Scanning: Principles and Processing. Boca Raton, FL: Taylor and Francis

Zlot, R., Bosse, M., 2014. Three-dimensional mobile mapping of caves. Journal of Cave and Karst Studies, v. 76, no. 3, p. 191-206.

Zlot, R., Bosse, M., Greenop, K., Jarzab, Z., Juckes, E., Robert, J., 2013. Efficiently Capturing Large, Complex Cultural Heritage Sites with a Handheld 3D Mobile Laser Mapping System. In: Journal of Cultural Heritage. 